\title{
Antibodies against citrullinated proteins enhance tissue injury in experimental autoimmune arthritis
}

\author{
Kristine A. Kuhn, ${ }^{1}$ Liudmila Kulik, ${ }^{2}$ Beren Tomooka, ${ }^{3,4}$ Kristin J. Braschler, ${ }^{2}$ \\ William P. Arend, ${ }^{2}$ William H. Robinson, ${ }^{3,4}$ and V. Michael Holers ${ }^{1,2}$
}

\begin{abstract}
1Department of Immunology and 2Department of Medicine, University of Colorado Health Sciences Center, Denver, Colorado, USA. ${ }^{3}$ Division of Immunology and Rheumatology, Department of Medicine, Stanford University School of Medicine, Stanford, California, USA.

${ }^{4}$ Geriatric Research, Education and Clinical Center, Palo Alto Veterans Affairs Health Care System, Palo Alto, California, USA.
\end{abstract}

\begin{abstract}
Antibodies against citrullinated proteins are specific and predictive markers for rheumatoid arthritis although the pathologic relevance of these antibodies remains unclear. To investigate the significance of these autoantibodies, collagen-induced arthritis (CIA) in mice was used to establish an animal model of antibody reactivity to citrullinated proteins. DBA/1J mice were immunized with bovine type II collagen (CII) at days 0 and 21, and serum was collected every 7 days for analysis. Antibodies against both CII and cyclic citrullinated peptide, one such citrullinated antigen, appeared early after immunization, before joint swelling was observed. Further, these antibodies demonstrated specific binding to citrullinated filaggrin in rat esophagus by indirect immunofluorescence and citrullinated fibrinogen by Western blot. To evaluate the role of immune responses to citrullinated proteins in CIA, mice were tolerized with a citrulline-containing peptide, followed by antigen challenge with CII. Tolerized mice demonstrated significantly reduced disease severity and incidence compared with controls. We also identified novel murine monoclonal antibodies specific to citrullinated fibrinogen that enhanced arthritis when coadministered with a submaximal dose of anti-CII antibodies and bound targets within the inflamed synovium of mice with CIA. These results demonstrate that antibodies against citrullinated proteins are centrally involved in the pathogenesis of autoimmune arthritis.
\end{abstract}

\section{Introduction}

The diagnosis and classification of rheumatoid arthritis (RA) is based on clinical and radiological findings with the support of a positive test for rheumatoid factor (RF) (1), an autoantibody to the constant region of IgG immunoglobulin. While RF is fairly sensitive for RA, detected in up to $80 \%$ of patients, this autoantibody lacks specificity. Sera from patients with other autoimmune disorders or infectious diseases as well as up to $15 \%$ of the healthy, elderly population demonstrate the presence of RF (2). Other less sensitive but more specific autoantibodies, such as the anti-perinuclear factor and anti-keratin antibody (AKA), also have been described in patients with RA (2-5). Importantly, upon further investigation, the anti-perinuclear factor and AKA were shown to bind a specific protein, filaggrin, found within keratohyalin granules and cornified epithelium $(6,7)$.

Filaggrin is produced in the late stages of terminal differentiation of epithelial cells during keratinization. The precursor profilaggrin is produced and stored in granules until terminal differentiation. At this point, profilaggrin is proteolytically cleaved and dephosphorylated, and certain arginine residues are deiminated by specific peptidylarginine deiminases (PADs) to form citrulline residues (8-11). When arginine residues within peptide sequences derived from filaggrin were deiminated in vitro, these peptides

Nonstandard abbreviations used: ABTS, 2,2'-azinobis(3-ethylbenzthiazoline-6sulfonic acid); AKA, anti-keratin antibody; APF, anti-perinuclear factor; CCP, cyclic citrullinated peptide; CIA, collagen-induced arthritis; CII, bovine type II collagen; LKP, linear lysine peptide; LRP, linear arginine peptide; LXP, linear citrullinated peptide; $\mathrm{PAD}$, peptidylarginine deiminase; $\mathrm{RF}$, rheumatoid factor

Conflict of interest: The authors have declared that no conflict of interest exists. Citation for this article: J. Clin. Invest. 116:961-973 (2006). doi:10.1172/JCI25422. were recognized by RA sera $(12,13)$. Using the most strongly reactive peptide, designated cyclic citrullinated peptide (CCP), an ELISA that measured antibodies against CCP demonstrated $68 \%$ sensitivity and $98 \%$ specificity for RA (14). Further studies indicated that anti-CCP antibodies may be present for many years before the onset of clinically apparent disease $(15,16)$.

Filaggrin is not expressed in the synovium. However, within the inflamed synovium of patients with RA, one potentially relevant antigen is citrullinated fibrin. Antibodies from patients with RA bind fibrin on Western blot analysis of rheumatoid synovial extracts. In addition, antibodies from patients with RA preferentially bind citrullinated fibrin as compared with noncitrullinated fibrin (17). Other citrullinated proteins, such as vimentin $(18,19)$, are also recognized by sera from patients with RA in a citrulline-specific manner. Thus, these antibodies are specific to the posttranslational citrullination and recognize this amino acid in the context of flanking amino acid sequences in at least 3 proteins. Despite these clinical associations, the immunopathologic events that lead to the development of autoantibodies against citrullinated proteins and whether these autoantibodies are pathogenic remain unknown.

Collagen-induced arthritis (CIA) is an animal model of inflammatory arthritis established by immunizing mice with bovine type II collagen (CII) emulsified in incomplete Freund's adjuvant containing Mycobacterium tuberculosis (20). Because the immunologic and histopathologic lesions in CIA resemble those observed in RA (20), CIA is one model in which the pathogenesis of RA can be studied. The initial processes of disease pathogenesis require $\mathrm{T}$ cells since $\mathrm{T}$ cell-deficient mice are not susceptible to CIA (21, $22)$. In addition, highly efficient presentation of the collagen antigen requires the I-Aq MHC class II allele $(23,24)$. T cell acti- 
A
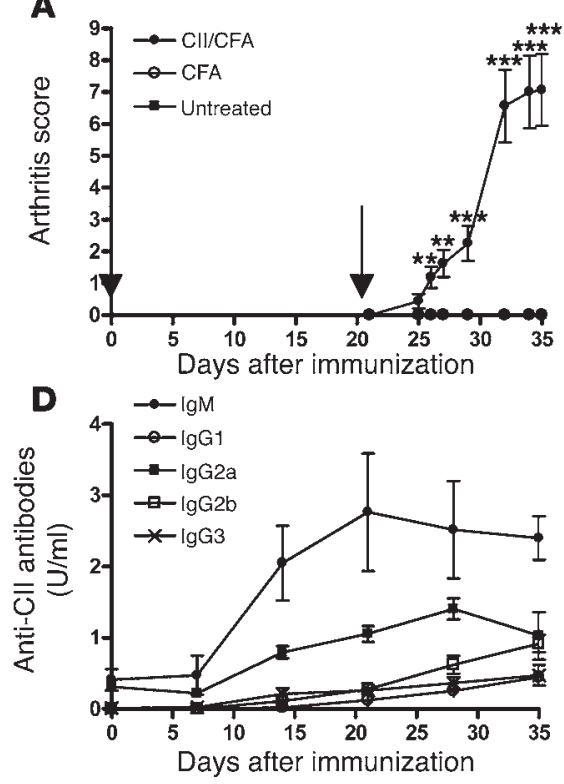
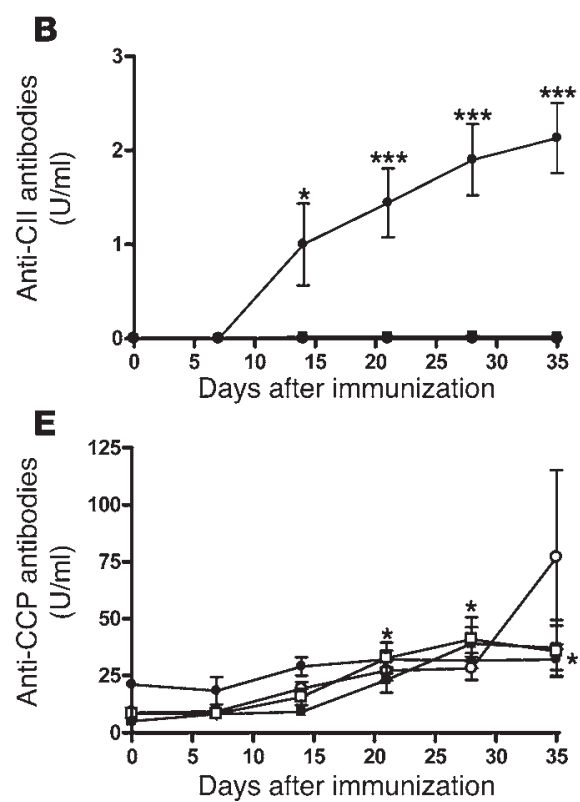
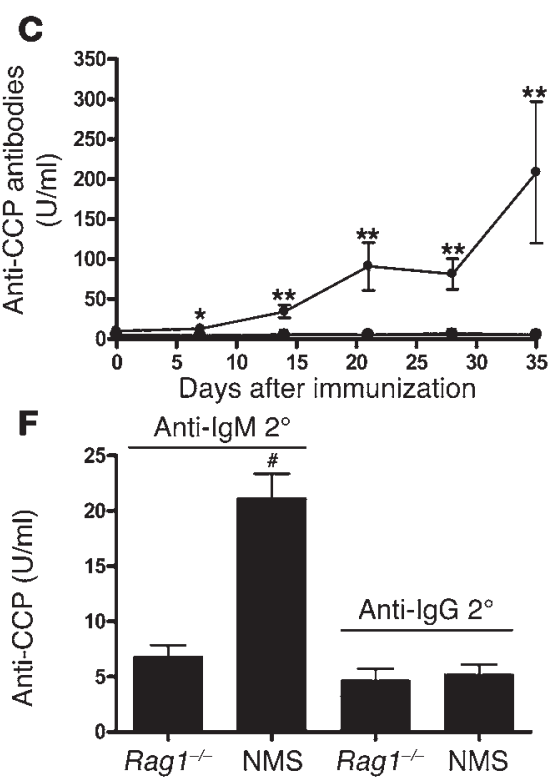

Figure 1

Anti-CCP antibodies appear prior to visible arthritis and in parallel with the appearance of anti-collagen antibodies. (A) Six- to 8-week-old DBA/1J mice were untreated or were immunized at day 0 with CII in CFA or CFA alone and then received booster immunizations 21 days later (black arrows). Sera were collected every 7 days and analyzed for antibody levels. Mice were also observed and scored for development of clinical arthritis. Visible signs of arthritis were measured by adding the number of swollen digits on all 4 paws of each mouse. (B) IgG and (D) isotype-specific antibodies against CII were measured by ELISA as described in Methods. (C) IgG and (E) isotype-specific anti-CCP antibodies were measured by ELISA as described in Methods. IgG3 anti-CCP antibodies were below the limits of detection by ELISA and thus are not shown. The data for each mouse within a group are averaged for that group and represented \pm SEM. For each group, $n=12$. Statistical significance was determined using a 1-way ANOVA. ${ }^{\star} P<0.05 ;{ }^{* \star} P<0.01 ;{ }^{* \star *} P<0.001$ in CIA mice compared with CFA-immunized and unimmunized mice. (F) Sera from Rag1 ${ }^{-l-}$ mice $(n=5)$ were tested and compared with unimmunized DBA/1J (normal mouse serum (NMS); $n=7$ for $\operatorname{lgM}$ and $n=23$ for lgG). Statistical significance was determined using an unpaired 2-tailed Student's $t$ test. ${ }^{\#} P=0.0004$ for IgM anti-CCP antibodies in NMS versus Rag ${ }^{-/-}$mice.

vation leads to an inflammatory Th1 response both systemically and within the joints (25-27). Chronic inflammation in CIA is largely due to complement-fixing anti-CII antibodies whose production is driven by autoreactive $\mathrm{T}$ cells. Anti-CII antibodies in CIA initiate joint damage by binding collagen in articular cartilage and activating complement.

Because the relevance of autoantibodies reactive with citrullinated antigens to the pathophysiology of RA remains unknown and a valid animal model in which to study these antibodies could provide substantial insights into these issues, we investigated the development and pathogenic potential of these antibodies in murine CIA. We demonstrate herein the presence of anti-citrullinated protein antibodies in CIA and show that they play a key role in the maximal development of inflammatory arthritis. In addition, autoantibodies against citrullinated proteins can greatly amplify tissue injury in the presence of a submaximal immune and inflammatory insult.

\section{Results}

Antibodies specific to citrullinated antigens develop in CIA in parallel with anti-CII antibodies and before visible artbritis. To determine if antibodies against citrullinated antigens are present in CIA, we immunized 6to 8-week-old male DBA/1J mice with CII emulsified in CFA or with CFA alone on days 0 and 21. Beginning at 25 days after the initial immunization with CII in CFA, mice developed clinical evidence of arthritis (Figure 1A). Serum was collected from mice every 7 days following the first immunization and was analyzed by ELISA for the development of autoantibodies against CII and CCP (Figure 1, $\mathrm{B}$ and C). Anti-CII antibodies began to develop around day 7 after the first immunization and steadily increased throughout the study. Similarly, anti-CCP reactivity appeared at 7 days after the first immunization and plateaued at day 21 . In both cases, the autoantibodies appeared prior to any signs of clinical disease.

To further characterize the development of CCP reactivity in CIA, we analyzed the isotypes of CII- and CCP-reactive antibodies. Strong IgM and IgG2a anti-CII antibodies developed after immunization along with less pronounced IgG1, IgG2b, and IgG3 responses (Figure 1D), consistent with previous reports (28). AntiCCP antibodies of the IgM, IgG1, IgG2a, and IgG2b isotypes developed after immunization with CII (Figure 1E) while IgG3 was not detected (data not shown). Intriguingly, anti-CCP IgM antibodies were readily detectable in preimmune sera, suggesting the presence of natural antibodies in mice toward a citrullinated antigen, and increased significantly after immunization $(P<0.05$ at day 14 and thereafter). To ensure that the relatively high IgM anti-CCP titer in naive mice was due to antibody and not to nonspecific serum reactivity detected by ELISA, we tested serum from Rag $1^{-/-}$mice, which are genetically unable to generate antibodies. Rag $1^{-/-}$mice demonstrated significantly lower anti-CCP IgM reactivity compared with unimmunized DBA/1J mice (Figure $1 \mathrm{~F}$ ). No difference in the level of anti-CCP IgG was detected between Rag1-/- sera and sera from unimmunized DBA/1J mice, indicating that approximately $7 \mathrm{U} / \mathrm{ml}$ is the lower limit of detection for analysis of mouse sera with the CCP ELISA (Figure 1F). 

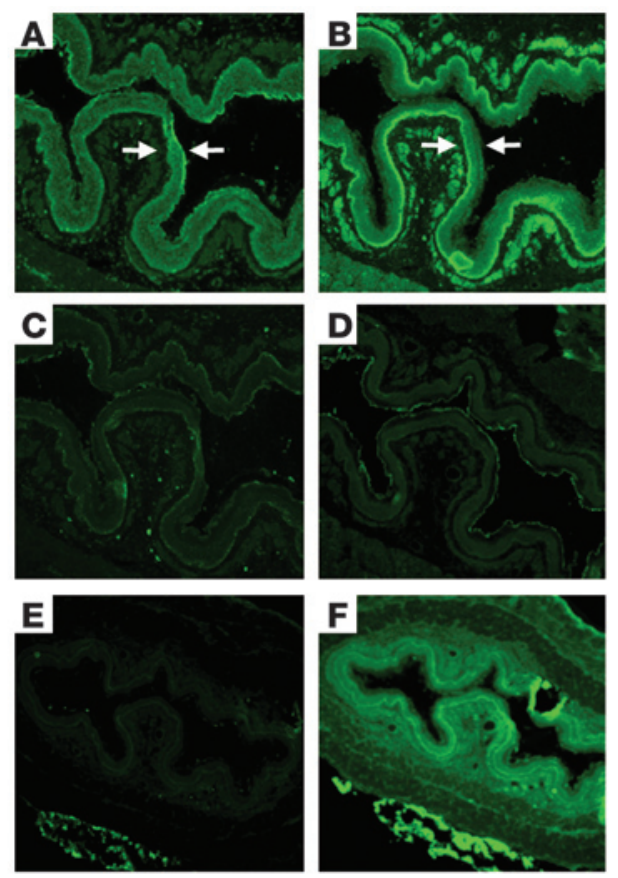

G

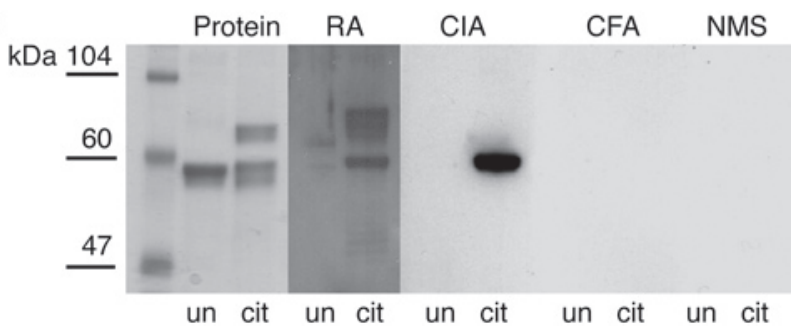

One additional means by which citrullinated protein reactivity is detected in patients with RA is indirect immunofluorescence on rat esophageal epithelium. It has been shown that AKA, anti-filaggrin, and anti-CCP antibodies in RA patient sera react with citrullinated filaggrin in the rat esophageal epithelium $(7,12)$. To assess this antibody reactivity in CIA, we applied sera from arthritic and control mice to sections of rat esophagus. Sera from arthritic mice on day 35 after the initial immunization demonstrated a staining pattern similar to that seen with RA sera while sera from adjuvant control and unimmunized mice did not demonstrate similar reactivity (Figure 2, A-D).

Observed CCP reactivity in CIA is specific to the citrulline modification. The key feature of reactivity in serum from patients with RA to these antigens is its marked specificity toward citrullinated epitopes rather than toward the unmodified protein that lacks citrulline residues $(12,14)$. The specificity of antibody binding in CIA sera was evaluated using peptide blocking of antibody reactivity. Serum obtained on day 35 after the initial immunization with CII in CFA was diluted in PBS or PBS containing $100 \mu \mathrm{g} / \mathrm{ml}$ linear citrullinated peptide (LXP) or $100 \mu \mathrm{g} / \mathrm{ml}$ of the control, linear arginine peptide (LRP), and applied to rat esophageal tissue sections. The LXP inhibited reactivity in both RA sera (data not shown) and CIA sera whereas the control LRP peptide did not (Figure 2, E and F). These results strongly suggest that the reactivity in mice with CIA to filaggrin in this tissue is specific to citrullinated filaggrin, as seen in patients with RA.

Citrullinated fibrin has been identified as a target antigen within the inflamed RA synovium, and antibodies specific to citrullinated

\section{Figure 2}

A population of antibodies in CIA is specific for the citrullinated proteins filaggrin and fibrinogen. (A) Sera from an RA patient; (B) CIA, day 35 after immunization; (C) adjuvant control; or (D) an untreated mouse were applied to tissue sections of rat esophagus. Arrows indicate areas of reactivity on epithelium. (E) Mouse sera from arthritic mice on day 35 after immunization were preabsorbed with citrullinated peptide (LXP) or (F) control peptide (LRP). These were then applied to tissue sections of rat esophagus. Serum antibody binding was detected with FITC-conjugated goat anti-mouse IgG. Magnification, $\times 40$. (G) Western blot of unmodified (un) and citrullinated (cit) fibrinogen probed with RA patient or mouse sera. In second and third lanes, proteins are stained with Coomassie to demonstrate relatively equal transfer for Western blot analysis.

fibrin are readily detected in the sera of RA patients (17). Therefore, as a second measure for citrulline specificity of the antibodies in CIA, we tested sera for reactivity against citrullinated fibrinogen. Pooled sera from individuals with RA, from mice immunized with CII in CFA or with CFA only, or from normal mouse serum were studied by Western blot analysis using unmodified and citrullinated fibrinogen. The only reactivity observed was against citrullinated fibrinogen in sera from patients with RA and mice with CIA (Figure $2 \mathrm{G}$ ), providing additional support for the specificity of the autoantibodies in CIA for citrullinated antigens.

Some lupus models demonstrate anti-CCP reactivity but without citrulline specificity. Another striking feature of reactivity to citrullinated antigens is the specificity of this autoantibody response for patients with RA. Other forms of arthritis and autoimmune diseases lack these antibodies (14). To evaluate the specificity of antibodies against citrulline-modified targets for CIA, we measured CCP reactivity in 2 murine models of lupus: SNF1 and MRL/lpr. In agreement with other studies (29), MRL/lpr mice at 4 months of age $(n=5)$ produced high titers of anti-CCP antibodies (Supplemental Figure 1, A and B; supplemental material available online with this article; doi:10.1172/JCI25422DS1). Anti-CCP antibodies were not observed in 4-month-old SNF1 mice $(n=4)$. Indirect immunofluorescence indicated the presence of MRL/lpr serum reactivity in the epithelium of rat esophagus; however, in contrast to mice with CIA, both LRP and LXP inhibited this serum binding (Supplemental Figure 1C). This observation suggested that the anti-CCP reactivity observed in MRL/lpr mice did not exhibit specificity for citrullinated filaggrin, thus differing from the autoantibody pattern observed in CIA. In addition, a Western blot of citrullinated and unmodified fibrinogen probed with pooled $\mathrm{MRL} / \mathrm{lpr}$ sera failed to demonstrate serum reactivity with either form of fibrinogen (data not shown), further supporting a difference between the specificity of anti-CCP reactivity in mice with CIA as compared with MRL/lpr mice.

Tolerance to a citrulline-containing epitope partially protects mice from CIA. Tolerance of mice to pathogenic epitopes of CII has been shown to protect mice from developing arthritis when subsequently challenged with this antigen $(30,31)$. Therefore, if citrulline-containing epitopes contributed to the disease process, we reasoned that tolerance to such epitopes would reduce disease severity and incidence. To test this hypothesis, $0.3 \mathrm{mg}$ of CII, ovalbumin, LXP, or linear lysine peptide (LKP) was administered intravenously for 3 days to 6-week-old male DBA/1J mice to induce tolerance to these antigens. LXP is a 19 amino acid peptide derived from human filaggrin that contains a single citrulline residue and 4 arginines 
A

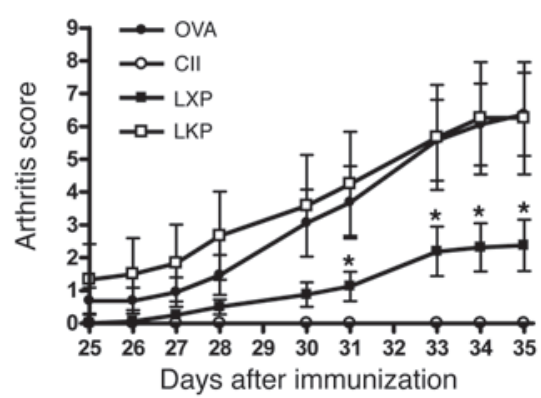

D

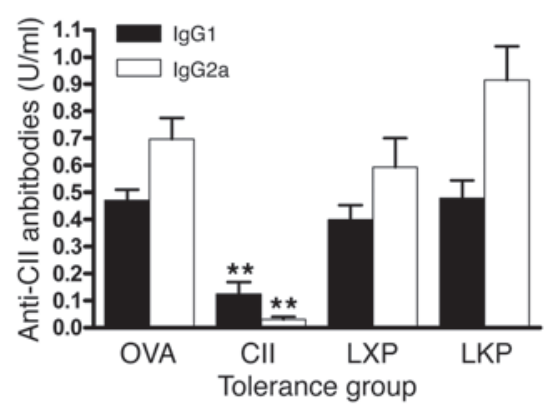

B

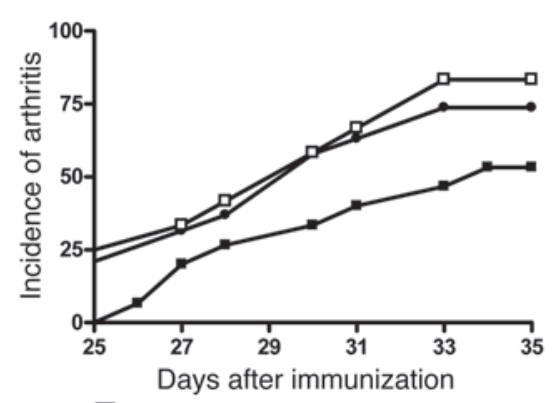

E

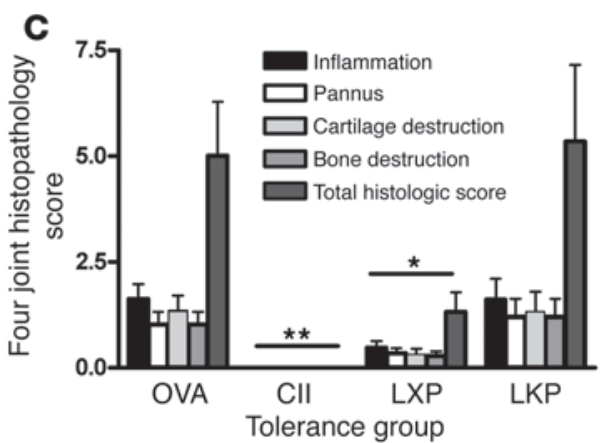

$\mathbf{F}$

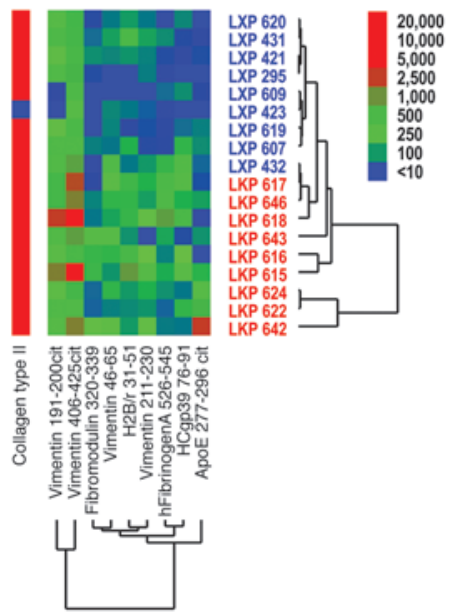

Figure 3

Mice tolerized with a citrullinated peptide are significantly protected from CIA. (A and B) Six- to eight-week-old male DBA/1J mice were tolerized to OVA $(n=19), \operatorname{CIl}(n=16), \operatorname{LXP}(n=16)$, or LKP $(n=12)$. After challenging these mice with immunization of Cll in CFA, disease severity $(\mathbf{A})$ and incidence (B) were measured. (C) Paws from mice in each tolerance group were analyzed for histologic parameters of arthritis as described in Methods. (D) Anti-CII antibodies were measured by ELISA, and (E) antibodies against citrullinated fibrinogen were determined by Western blot. All data are shown as group averages \pm SEM. Statistical significance was determined by 1 -way ANOVA. ${ }^{*} P<0.05 ;{ }^{* \star} P<0.01$ in comparison with the OVA and LKP groups. (F) Sera from tolerized mice were applied to synovial antigen arrays to characterize the autoantibody response. The relative reactivities for the labeled antigens in a pool of sera from 9 mice in each LXP- and LKP-tolerized group are shown, as is the clustering of mice based on the relationships of antibody reactivity between the mice.

(12). Since any arginine residue may become deiminated in vivo by endogenous PADs, a lysine-substituted peptide (LKP), which maintains the overall charge of the peptide while eliminating the possibility of becoming deiminated in vivo, was chosen as a control for these experiments.

Three days following the last dose of tolerogen, mice were challenged on days 0 and 21 with CII in CFA to induce CIA. As shown previously (30), disease in mice tolerized with ovalbumin was not affected while mice tolerized with CII failed to develop arthritis (Figure 3, A and B). CIA development in mice tolerized with the control LKP peptide was also unaffected whereas the severity of disease in LXP-tolerized mice was significantly reduced, by approximately $60 \%$, compared with the ovalbumin and LKP-tolerized groups (Figure 3A). Further, the incidence of CIA in LXP-tolerized mice was also reduced (Figure $3 \mathrm{~B}$ ). Histologic evaluation of the joints from these mice confirmed the clinical phenotype, demonstrating significantly reduced inflammation, pannus formation, and cartilage and bone destruction in the LXP-tolerized mice compared with ovalbumin- and LKP-tolerized controls (Figure 3C). As expected, induction of tolerance with $\mathrm{CII}$ led to significant reductions in anti-CII antibody levels ( 74\% IgG1 and $\sim 96 \%$ IgG2a;
Figure 3D). However, anti-CII antibody levels were unaffected in the other groups. Western blot analysis revealed that antibodies against citrullinated fibrinogen were reduced in the CII- and LXP-tolerized groups but unaffected in the ovalbumin and LKP control groups (Figure 3E). In these groups of mice, antibody reactivity against additional unmodified and citrullinated antigens was measured using synovial antigen arrays (19) (please note that peptide sequences used in Figures 3 and 4 are in Supplemental Table 1). Mice tolerized with LXP compared with LKP and OVA exhibited a decrease in epitope spreading to both citrullinated and native epitopes (Figure $3 \mathrm{~F}$ and data not shown). We also observed reduced epitope spreading in CII-tolerized mice compared with OVA and LKP-tolerized groups (data not shown). From these data, we conclude that immune responses to citrullinated proteins are important to the development of inflammatory arthritis.

Monoclonal antibodies specific to citrullinated fibrinogen enhance arthritis. As a further test of the pathogenic potential of antibodies against citrullinated proteins, we determined whether antibodies against these autoantigens would enhance disease. To accomplish this, we first identified monoclonal antibodies specific to citrullinated fibrinogen. We then transferred them alone and in combination 

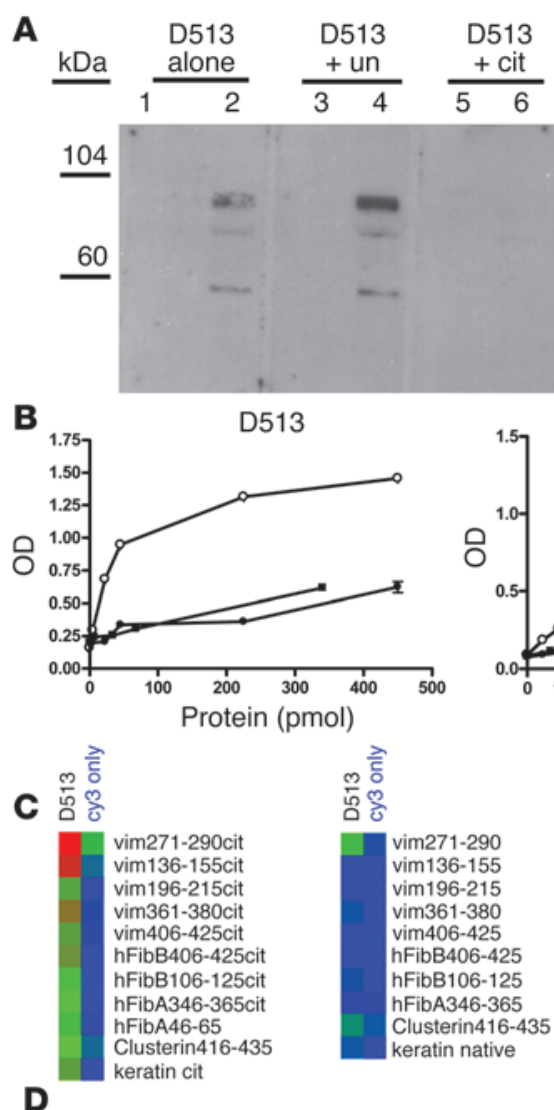

D

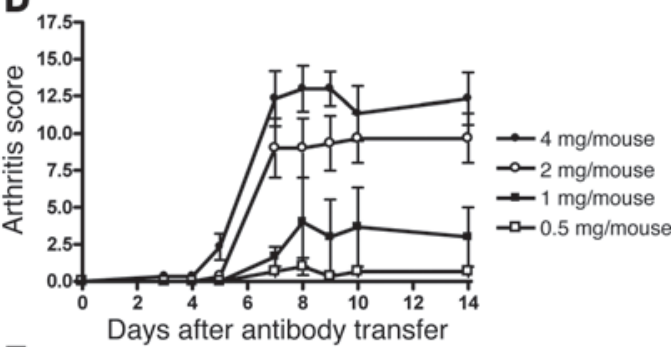

E

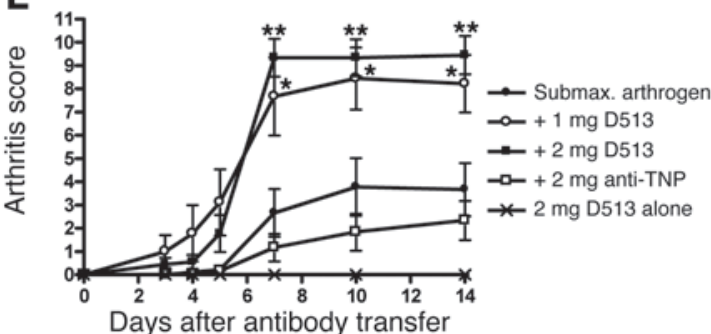

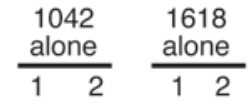

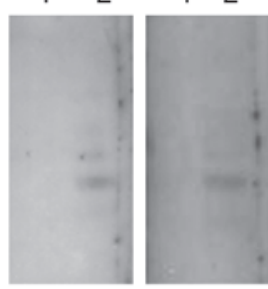

1042
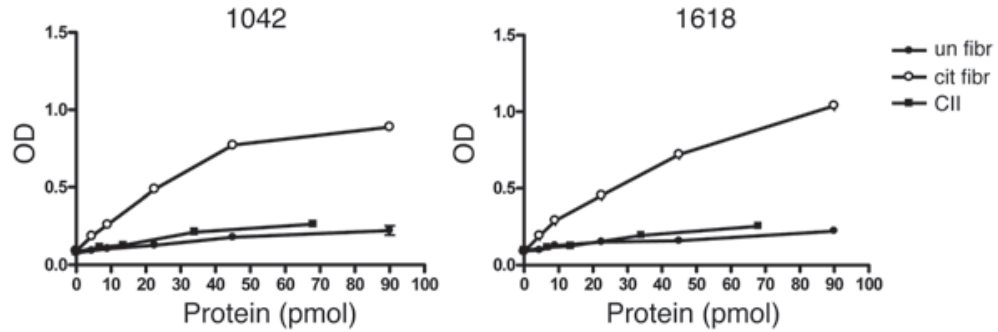
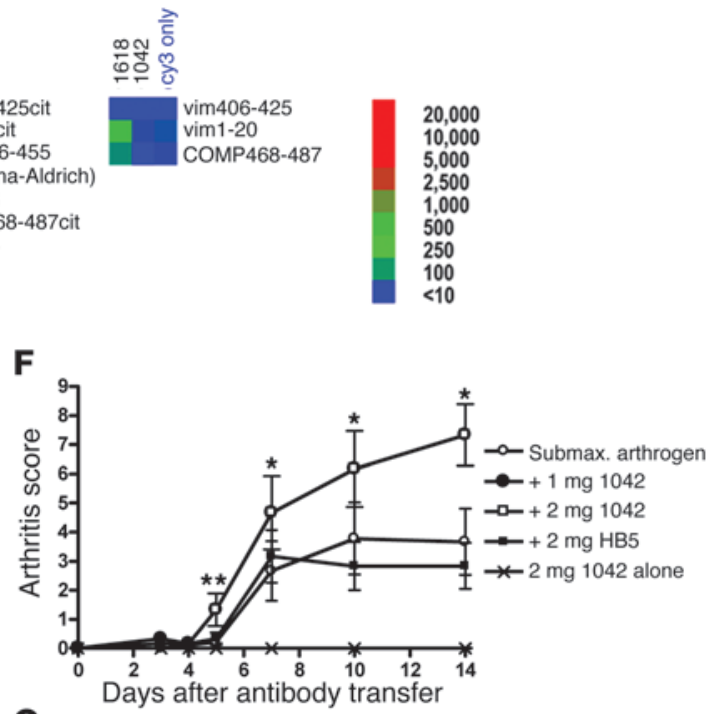

G

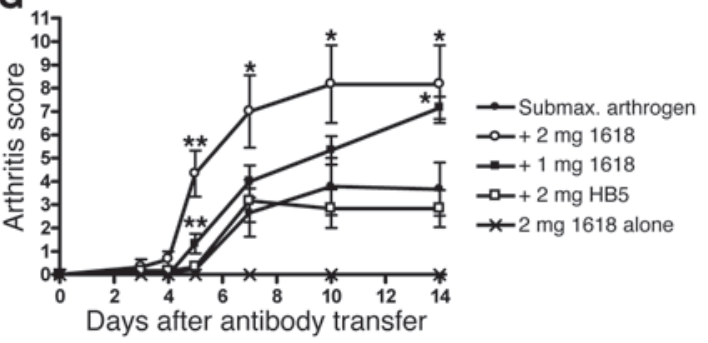

Figure 4

Antibodies specific to citrullinated fibrinogen substantially enhance submaximal arthritis. (A) Purified D513, 1042, or 1618 monoclonal antibody was applied to a Western blot of unmodified and citrullinated fibrinogen. To compete for antigen binding on the blot, soluble unmodified or citrullinated fibrinogen was added to D513 prior to applying the antibody to the Western blot. (B) The relative reactivities of the monoclonal antibodies for unmodified and citrullinated fibrinogen were determined by applying increasing amounts of biotinylated unmodified and citrullinated fibrinogen (fibr) and CII to ELISA plates coated with monoclonal antibody. The amount of protein binding was detected as described in Methods and is displayed as OD. (C) Additional antigens recognized by D513, 1042, and 1618 were detected using synovial antigen arrays. The relative reactivity for the antigens recognized is shown. (D) Arthrogen, a cocktail of 4 monoclonal antibodies against CII, was transferred intravenously into 6- to 8-week-old male DBA/1J mice at increasing doses followed by $50 \mu \mathrm{g}$ LPS intraperitoneally 3 days later in order to determine which dose would establish submaximal disease. $n=3$ per dose group. (E) D513 $(n=9)$ or control monoclonal antibody $(n=6)$ were administered alone or in combination with the submaximal dose of Arthrogen (1 mg). (F and $\mathbf{G})$ Either $1 \mathrm{mg}$ or $2 \mathrm{mg}$ of monoclonal antibody 1042 or $1618(n=6)$ or 2 mg HB5 control monoclonal antibody $(n=6)$ was combined with $1 \mathrm{mg}$ of Arthrogen and transferred into mice as performed previously with D513. Data shown are the average disease score per group \pm SEM. Statistical significance was determined using 1 -way ANOVA. ${ }^{*}<0.05$; ${ }^{* *} P<0.01$ in comparison with submaximal Arthrogen alone. 
A

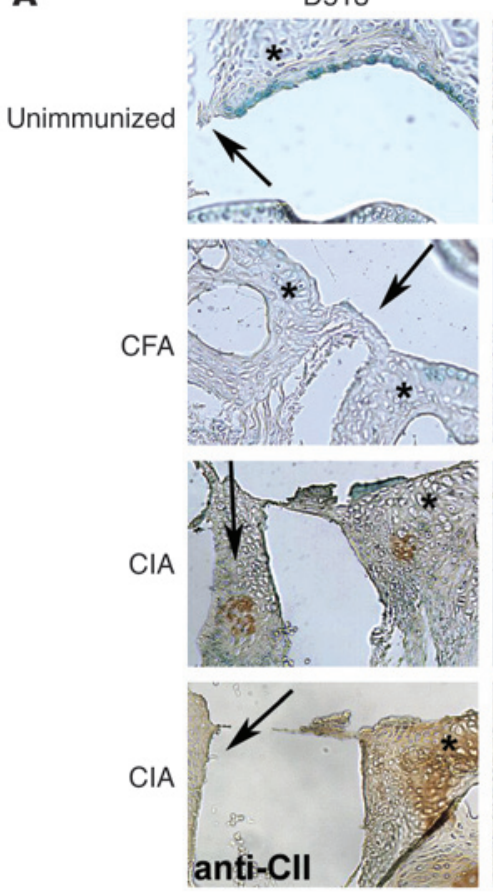

B

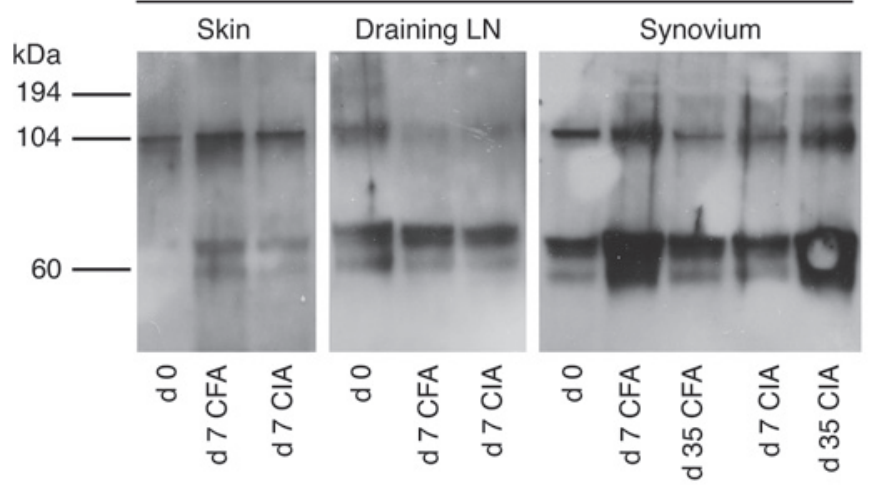

1042
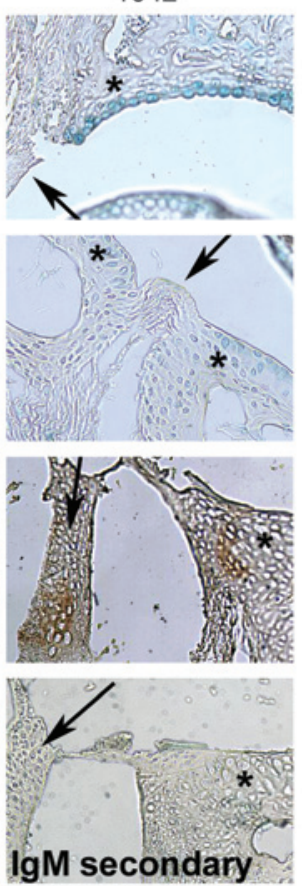

1618
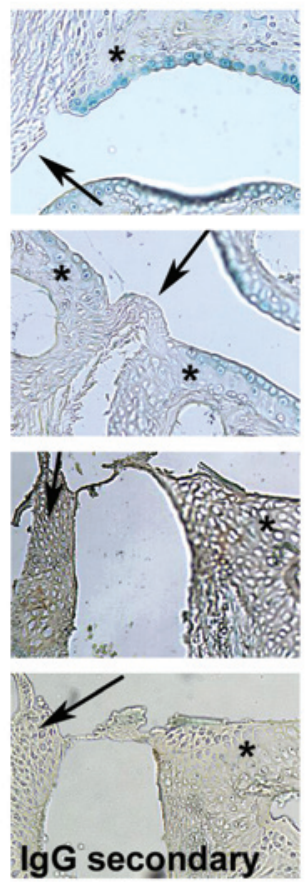

C 1042

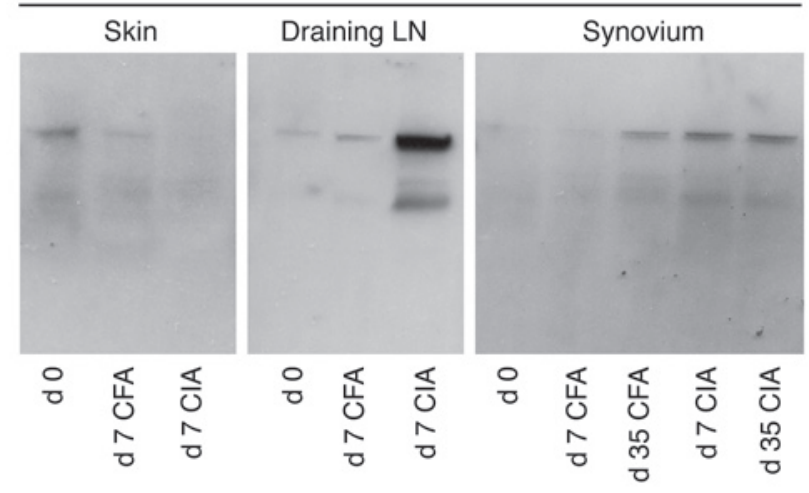

Figure 5

D513, 1042, and 1618 monoclonal antibodies bind antigens within the inflamed synovium of mice with CIA. (A) Immunohistochemistry was per-

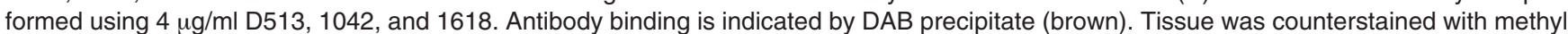
green. A mix of anti-CII monoclonal antibodies and secondary reagents without primary antibody served as negative controls for staining the synovium. Representative serial sections are shown. Magnification, $\times 100$. Arrows point to synovium, and asterisks indicate cartilage. (B) Skin from the site of immunization, draining inguinal LN, and synovium were collected from unimmunized mice, mice immunized with CFA, or mice with $\mathrm{CIA}$ at different time points. Western blots of the protein isolated from these tissues were performed with a polyclonal antibody that recognizes the amino acid citrulline or (C) with the monoclonal antibodies 1042, 1618, and D513. Representative blots are shown. Results of Western blots probed with antibodies 1618 and D513 were essentially identical to 1042 and, thus, are not shown.

with a cocktail of anti-CII antibodies into mice. To develop an antibody specific to a citrullinated protein, and noting the presence of natural IgM antibodies with this specificity (Figure 1F), we screened a previously created panel of IgM-producing hybridomas established from naive C57BL/6 splenocytes for antibody specificity to citrullinated fibrinogen. One clone, D513, demonstrated such specific reactivity by Western blot analysis (Figure 4A). To confirm that the D513 epitope was present in the native conformation of citrullinated fibrinogen, we determined whether the reactivity of D513 on the Western blot could be blocked by preincubating the antibody with soluble unmodified fibrinogen or citrullinated fibrinogen. We found that only the addition of citrullinated fibrinogen to the antibody could block reactivity on the Western blot (Figure 4A). As a demonstration of the relative affinity of D513 for soluble unmodified and citrullinated fibrinogen and a control protein, CII, $0.5 \mu \mathrm{g}$ monoclonal antibody was bound to Immulon $2 \mathrm{HB}$ plates, and increasing amounts of biotinylated proteins were added to the bound antibody. D513 had high affinity for native citrullinated fibrinogen but did not bind either unmodified fibrinogen or CII (Figure 4B). Finally, we identified additional antigens for D513 by applying the monoclonal antibody to the synovial antigen array (Supplemental Table 1). D513 

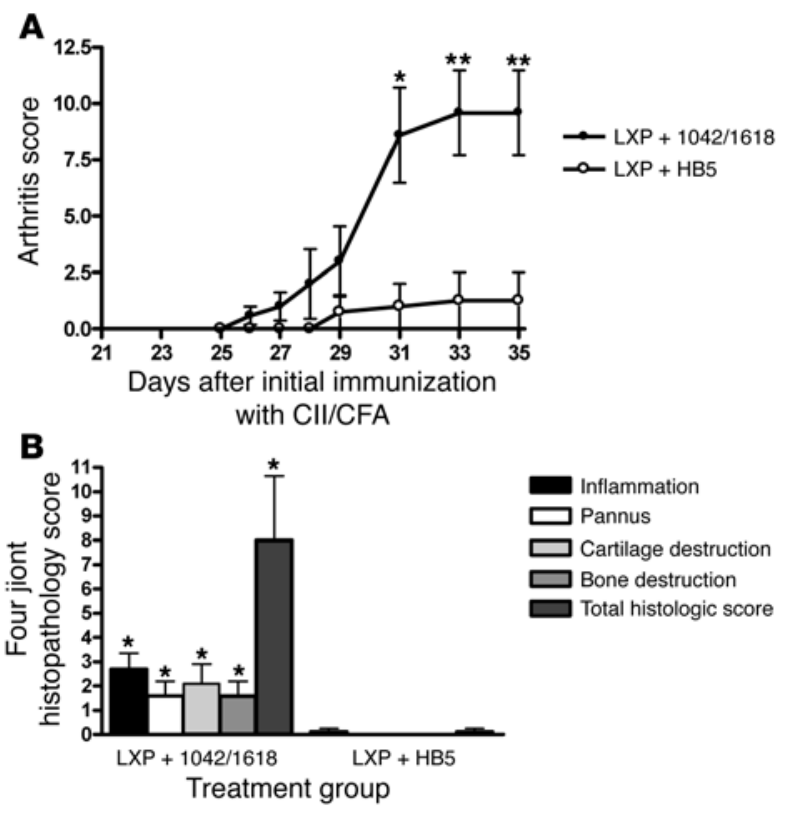

bound several citrullinated fibrinogen peptides as well as citrullinated forms of vimentin, clusterin, and keratin (Figure 4C). In additional experiments, D513 did not react with typical targets of cross-reactive natural antibodies, including double-stranded DNA, single-stranded DNA, and phospholipids (data not shown). These results in toto demonstrate that D513 specifically binds citrullinated epitopes derived from fibrinogen and other antigens.

To measure the pathogenic potential of D513, we transferred $2 \mathrm{mg}$ of purified antibody intravenously into 6- to 8-week-old DBA/1J mice, followed by $50 \mu \mathrm{g}$ LPS 3 days later. None of the mice developed any visible signs of arthritis (Figure 4E). We then asked whether an antibody to citrullinated fibrinogen could contribute to tissue injury by enhancing submaximal disease established by a cocktail of monoclonal antibodies against CII (Arthrogen). To determine a submaximal dose of anti-CII antibodies, increasing doses of Arthrogen were administered to 6- to 8 -week-old male DBA/1J mice followed by $50 \mu \mathrm{g}$ LPS 3 days later (Figure 4D). One milligram of Arthrogen induced very mild disease and was therefore chosen to use in combination with $1 \mathrm{mg}$ and $2 \mathrm{mg}$ D513. The addition of both $1 \mathrm{mg}$ and $2 \mathrm{mg}$ D513 to $1 \mathrm{mg}$ Arthrogen significantly increased the severity of arthritis by more than 2.5 fold (Figure 4E). To demonstrate that the enhancement of disease was due to D513 and not to an overall increase in total Ig administered, we also transferred $2 \mathrm{mg}$ of a monoclonal IgM specific to trinitrophenol-KLH (TNP) in combination with $1 \mathrm{mg}$ Arthrogen. This treatment did not result in a significant enhancement of disease (Figure 4E).

Finally, we identified 2 IgG2a monoclonal antibodies, 1042 and 1618 , from a fusion of splenocytes and LN cells, respectively, from DBA/1J mice with CIA that were specific to citrullinated fibrinogen (Figure 4, A and B) as well as for citrullinated peptides derived from filaggrin and vimentin (Figure $4 \mathrm{C}$ ). To demonstrate that the citrullinated fibrinogen-specific IgG antibodies that appear in CIA are indeed pathogenic, we transferred $1 \mathrm{mg}$ or $2 \mathrm{mg}$ of purified 1042 or 1618 in combination with $1 \mathrm{mg}$ Arthrogen into mice as described. Both monoclonal antibodies significantly accelerated and enhanced disease (Figure 4, F and G). Two milligrams

\section{Figure 6}

Antibodies against citrullinated fibrinogen can overcome the protective effect of tolerance to citrullinated antigens. Mice were tolerized with LXP, challenged twice with CII in CFA, and then administered either $2 \mathrm{mg}$ of equal amounts of 1042 and 1618 or $2 \mathrm{mg}$ of the control HB5 antibody on days 22 and 28 after the initial challenge with $\mathrm{CII}$ in CFA. (A) Arthritis scores were measured between days 21 and 35, and (B) histologic evaluation was performed on paws collected on day 35. Data are shown as group averages \pm SEM. Statistical significance was determined by 1 -way ANOVA. ${ }^{*} P<0.05$; ${ }^{* *} P<0.01$ in comparison with the LXP plus HB5 control group. Mice tolerized with LKP, challenged with CII in CFA, and given monoclonal antibodies 1042/1618 or HB5 served as additional controls. No difference was detected between these groups and the LXP plus 1042/1618 group (data not shown).

of a control IgG2a monoclonal antibody, HB5, which specifically recognizes human complement receptor 2 and not the murine homolog $(32,33)$, did not accelerate or enhance disease when combined with $1 \mathrm{mg}$ Arthrogen (Figure 4, F and G). These results further support the conclusion that antibodies specific to citrullinated proteins are pathogenic.

D513, 1042, and 1618 monoclonal antibodies bind target antigens in inflamed synovium. Citrulline-modified fibrinogen has been demonstrated to be present in the inflamed synovium of mice with CIA (34). To determine if the enhancement of arthritis by the transfer of monoclonal antibodies specific to citrullinated fibrinogen is due to their binding this antigen in the synovium, we performed immunohistochemistry on joint tissue sections from unimmunized mice, mice immunized with CFA, and mice that developed CIA following immunization with CII in CFA. All 3 monoclonal antibodies bound antigens within the pannus of mice with CIA but did not bind tissue from unimmunized or adjuvant control mice (Figure 5A). Anti-CII monoclonal antibodies (Arthrogen) were used for positive control staining of cartilage, where CII is located within the joint, and negative control staining of synovium. Our results are consistent with this expected pattern of staining for CII.

Additionally, we isolated proteins from the skin, draining inguinal LNs, and synovium of unimmunized mice, adjuvant control mice, and mice with CIA on days 7 and 35 after immunization. Equal protein amounts of cellular lysates were loaded into $10 \%$ Bis-Tris acrylamide gels (Supplemental Figure 2), and Western blot analysis of this protein was performed using a polyclonal anti-citrulline antibody and our anti-citrullinated protein monoclonal antibodies. Total citrullinated proteins, as indicated by the blot probed with the anti-citrulline polyclonal antibody, mildly increased in the synovium of mice administered CFA by day 7 after immunization, but by day 35 , total citrullinated protein was similar to synovium from unimmunized control mice. An increase in total citrullinated protein was not observed in synovium from mice with CIA on day 7 after immunization; however, by day 35, there was a readily apparent increase in citrullinated protein (Figure 5B). In synovia of mice with CIA, bands at approximately $60-70 \mathrm{kDa}$ and at approximately $105 \mathrm{kDa}$ greatly increased in intensity from day 0 to day 35 . No differences in skin or draining LNs were observed. Citrullinated antigens at approximately $70 \mathrm{kDa}$ and approximately $105 \mathrm{kDa}$ detected by our monoclonal antibody 1042 were also increased in the synovium by day 35 in mice with CIA (Figure 5C). A modest increase in citrullinated antigen detected by 1042 was also observed in the 
synovium from mice given CFA by day 35, but this increase was not as great as seen in synovium from mice with CIA on day 35 . Most intriguingly, though, the greatest increase in citrullinated antigens at approximately $70 \mathrm{kDa}$ and approximately $105 \mathrm{kDa}$ detected by 1042 was in the draining LNs on day 7 after immunization with CII in CFA. Western blot analyses with the monoclonal antibodies D513 and 1618 were equal to that with 1042 (data not shown). These data suggest that citrullinated antigens are presented in the draining LNs shortly after immunization with CII in CFA and could help to drive the development of antibodies against these citrullinated antigens. This additional citrullinated antigen-antibody interaction within the joint is the likely mechanism for amplification of disease.

Administration of antibodies against citrullinated fibrinogen can overcome protective tolerance induced by LXP. Our data suggest that tolerization of mice with LXP protects them from the full development of CIA by preventing epitope spreading to include antibody reactivity toward citrullinated antigens (Figure 3, E and F). Therefore, to determine if antibodies against citrullinated antigens could overcome the protection provided by tolerance to these antigens, we tolerized mice to LXP and challenged them with CII in CFA as before, then administered $2 \mathrm{mg}$ of equal amounts of 1042 and 1618 monoclonal antibodies or $2 \mathrm{mg}$ of HB5 control monoclonal antibody on days 22 and 28 after the initial immunization with CII in CFA. Treatment of tolerized mice with 1042 and 1618 led to the development of full disease while mice treated with the control HB5 monoclonal antibody remained protected from full arthritis, measured both clinically and histologically (Figure 6). We also used as controls mice tolerized with LKP, challenged with CII in CFA, and given either the 1042/1618 monoclonal antibody cocktail or the HB5 monoclonal antibody control. We did not observe significant differences in disease or histologic scores in these 2 groups compared with the LXP-tolerized group that received the 1042/1618 monoclonal antibodies (data not shown). In sum, we confirm that the protective effect of tolerance with LXP is indeed a decrease in the development of antibodies against citrullinated antigens, as replacement of antibodies against citrullinated antigens using the $1042 / 1618$ monoclonal antibodies specifically results in the redevelopment of severe arthritis.

\section{Discussion}

In this report, we demonstrate the importance of citrullinated proteins and antibodies against such self antigens for the development of inflammatory arthritis. Using 3 methods, antibodies against citrullinated antigens were detected in CIA and were shown to be specific to a citrulline-containing protein. Induction of tolerance to a citrullinated peptide led to a significant reduction in susceptibility to CIA upon challenge with CII, indicating that immune responses toward citrullinated antigens are involved in disease pathogenesis. Furthermore, monoclonal antibodies specific to citrullinated fibrinogen substantially enhanced arthritis when coadministered with anti-CII monoclonal antibodies and reversed the protection from inflammatory injury following induction of tolerance with a citrullinated peptide. We believe that these results in toto definitively demonstrate that antibodies against citrullinated proteins are important contributing factors in the development of inflammatory arthritis.

Antibodies in the serum of patients with RA have been shown to specifically target citrullinated filaggrin, fibrinogen, and vimentin. These antibodies have been detected, using indi- rect immunofluorescence, on the epithelium of rat esophagus, which contains citrullinated filaggrin $(7,12)$; by Western blot of the unmodified and citrullinated forms of fibrinogen (17) and vimentin (18); and by an ELISA with peptides (CCP) based on filaggrin sequences that contain citrulline residues (14). Using each of these methods, we were able to demonstrate the same citrulline-specific antigen reactivity in CIA. Our data validate this murine model of inflammatory arthritis for further investigation of the development and pathogenicity of antibodies against citrullinated proteins in RA.

As a first measure of the pathogenic potential of citrullinated antigens, we established tolerance to these antigens in mice followed by challenge with CII. We chose the LXP peptide as a citrullinated tolerogen because this peptide contained a single citrulline residue surrounded by a flanking amino acid sequence described in a population of RA patients to confer antibody reactivity (12, 13). Additionally, from our indirect immunofluorescence studies, LXP inhibited CIA serum reactivity with the epithelium of rat esophagus, suggesting that this peptide contained an epitope that was central to the citrulline-specific immune response. By tolerizing mice to LXP, mice were partially protected from CIA upon challenge with CII in CFA. The likely cause of this protection was a reduction of antibodies against citrullinated proteins. However, we cannot exclude tolerance of citrullinated-peptide specific $T$ cells, which may also contribute to the suppressed arthritis that was observed. Nevertheless, administration of antibodies against citrullinated proteins overcame tolerance and restored severe disease in mice, indicating that the production of antibodies against citrullinated proteins is the key pathogenic pathway leading to maximal arthritis.

To directly demonstrate the pathogenicity of antibodies specific to citrullinated proteins, we developed monoclonal antibodies specific to citrullinated fibrinogen (D513, 1042, and 1618) and transferred them into mice alone and in combination with antibodies against CII. These monoclonal antibodies alone could not induce arthritis at a dose of $2 \mathrm{mg}$ per mouse; however, this result was not surprising. One reason is that to induce arthritis by transfer of monoclonal antibodies against CII, a combination of at least 3 different antibodies, each recognizing distinctly different epitopes, is required (35). In addition, in another model of autoimmune arthritis, the transfer of antibodies specific to glucose-6-phosphate isomerase from $\mathrm{K} / \mathrm{BxN}$ mice also has been shown to require a minimum of 3 monoclonal antibodies against the targeted antigen for visibly apparent disease to be established in mice (36). Therefore, we used the arthrogenic anti-CII monoclonal antibody cocktail to establish minimal disease in mice, with arthritis becoming substantially more severe with the addition of D513, 1042, or 1618. It is likely that these monoclonal antibodies recognized citrullinated proteins in synovium, the presence of which has been previously described in CIA (34). Citrullinated proteins in the synovia were likely induced by the anti-CII monoclonal antibody cocktail. Our studies by immunohistochemistry of D513, 1042, and 1618 in inflamed synovium as well as Western blots of synovium from mice with CIA probed with antibodies against citrulline and citrullinated proteins are consistent with this conclusion (Figure 5).

Anti-CCP reactivity has also been demonstrated in other murine models of autoimmunity, namely in MRL/lpr mice $(29,37)$. Since $\mathrm{MRL} / \mathrm{lpr}$ mice may develop spontaneous arthritis (38), it is conceivable that anti-CCP antibodies would be present in these mice as part of the pathogenic processes leading to autoimmune arthritis. 
We confirmed the presence of anti-CCP antibodies in MRL/lpr mice and further characterized these antibodies. However, while the anti-CCP antibodies present in MRL/lpr mice consisted of the same isotypes as seen in CIA, anti-CCP antibodies in MRL/lpr mice lacked specificity for a citrullinated antigen. Therefore, our results are consistent with those of others (37) who have concluded that anti-CCP reactivity in MRL/lpr mice represents a different immunologic process than that present in RA.

Our results are in contrast with those of others (34) where antibodies against CCP and citrullinated fibrinogen were not detected in mice with CIA. Several possibilities may explain these differing observations. The mice in our study may have developed a more robust immune response after the initial immunization due to differences in the environment of animal housing facilities or in specific immunization techniques. The DBA/ 1 mice in our study were also obtained from a different source, and genetic drift may have occurred between the 2 sources, affecting the ability of the mice to produce antibodies against citrullinated proteins in response to CII immunization. In addition, we used different sources for secondary reagents in our studies.

Citrullination of proteins has been shown to break tolerance in mice. When immunized with human or murine fibrinogen, which are approximately $70 \%$ homologous in amino acid sequence, mice do not produce antibodies against the native protein. However, if the fibrinogen is treated with $\mathrm{PAD}$, such that it becomes citrullinated prior to immunization, mice develop a robust antibody response to the citrullinated protein (39). Furthermore, since PAD has not been shown to be expressed in the thymus (40), T cells reactive to citrullinated antigens are not likely to be negatively selected. Reasonably, deimination of self proteins could result in immune responses to self antigens that would otherwise not develop.

The response toward a citrullinated protein in CIA is likely to have arisen from an event during which protein was deiminated during or shortly after immunization. Antibodies against both CCP and CII occurred concurrently approximately 7 days following immunization with CII in CFA. However, adjuvant alone could not elicit an antibody response, suggesting that the CII antigen triggered an antibody response to citrullinated proteins. We were unable to detect the presence of citrulline in the CII used for immunization through either a diacetyl monoxime colorimetric assay (sensitivity of $10 \mathrm{nM}$ citrulline; ref. 41) or by amino acid analysis, which has a sensitivity of $0.02 \%$ of total CII amino acid content (data not shown). However, type II collagen does contain a core epitope suggested to confer CCP reactivity when the arginine is deiminated (amino acid sequence GRT, ref. 13; amino acids 148-150 in CII, amino acids 288-290 in murine type II collagen). Conceivably, many proteins became deiminated during or after immunization, which could also lead to the antibody responses to citrullinated antigens.

Two possible deimination events may have occurred after immunization of our mice. Either the mycobacteria in the adjuvant contained a PAD, or infiltrating neutrophils and macrophages that express PAD IV $(34,40,42)$ at the site of immunization or in the joint released the enzyme into the extracellular matrix during apoptosis. The former possibility is unlikely since no PAD has been described in mycobacteria, and the mycobacteria have been heat killed prior to use in the adjuvant. The latter possibility is more likely, especially in light of others' observations within the synovium of arthritic mice. Neutrophils expressing type IV PAD have been reported to migrate into the inflamed synovium of mice with
CIA or streptococcal wall arthritis concordant with the presence of citrullinated fibrinogen (34). These authors hypothesized that the infiltrating neutrophils released PAD into the extracellular matrix during apoptosis where calcium concentrations were sufficiently high to sustain enzymatic activity. As fibrin is a common constituent of the inflamed synovium, it may serve as a local substrate for $\mathrm{PAD}$, generating citrullinated antigens in situ.

In our model, one possible scenario is that local inflammation at either the site of injection or within the joint ensued shortly after immunization. Infiltrating neutrophils at this site underwent apoptosis and released PAD. Arginine within the injected $\mathrm{CII}$ or other local antigens such as fibrin may have become deiminated, leading to the selection of the antibodies against citrullinated proteins that were observed in murine CIA. We attempted to demonstrate an increase in citrullinated antigens in tissues after immunization. As skin contains filaggrin, which is known to be citrullinated, it is difficult to demonstrate an increase in citrullinated protein in this tissue. However, we did detect increased citrullinated protein of approximately $70 \mathrm{kDa}$ and approximately $105 \mathrm{kDa}$ in draining LNs from the site of immunization, suggesting that after immunization, protein(s) became citrullinated and were presented in the LNs. If mice were tolerized to LXP prior to immunization with CII, these antibody responses would be inhibited, resulting in decreased arthritis. The development of IgG antibodies against citrullinated antigens suggests this is a $\mathrm{T}$ cell-mediated process, though we have not formally evaluated this issue. Additionally, we observed increased citrulline and citrullinated protein of approximately $60-70 \mathrm{kDa}$ and approximately $105 \mathrm{kDa}$ in synovium of mice after immunization; however, this increase was not observed on day 7 after immunization with CII in CFA, but by day 35, indicating that significant citrullination of joint antigens occurred after the development of antibodies against citrullinated proteins. Thus, our data suggest the initial antigen(s) that drive the autoantibody response to citrullinated proteins originate outside the joint. Further studies are necessary, though, to evaluate this issue.

Regardless of how antibodies against citrullinated proteins develop and what their targets are, these antibodies contribute significantly to disease. After transfer of D513, 1042, or 1618, these monoclonal antibodies likely bind their antigen, citrullinated fibrinogen, within inflamed synovium. This would lead to further immune complex formation, complement activation, and neutrophil and macrophage production of proinflammatory molecules, thereby enhancing the inflammatory responses within the joint of mice and also enhancing visibly apparent disease.

The hypothesis that posttranslational modification of self proteins breaks tolerance is not limited to citrullination. Within the CIA model, another posttranslational modification has been described as important in breaking T cell tolerance to CII. A lysine residue at position 264 of CII may be posttranslationally modified through hydroxylation and galactosylation. Such posttranslational modification via glycosylation of lysine residues in CII can occur in the chondrocyte, resulting in a break in tolerance to $\mathrm{CII}$ in both humans and mice $(43,44)$. Treatment of neonatal mice with a galactosylated $\mathrm{CII}_{259-273}$ peptide protected mice from the development of CIA better than the unmodified peptide (43). Further, mice transgenic for human CII and DRB*0401/human CD4 were immunized with human $\mathrm{CII}$ and generated stronger recall $\mathrm{T}$ cell responses when restimulated with the galactosylated $\mathrm{CII}_{259-273}$ peptide (44). In another autoimmune system, phosphorylation of 
self proteins by serine/threonine kinases during apoptosis generates autoantigens recognized by sera from patients with systemic lupus erythematosus (45). Finally, in patients with celiac disease, deamidation of gliadin by tissue transglutaminase breaks $T$ cell tolerance to gliadin $(46,47)$, and the substrate-enzyme complex generates additional $\mathrm{T}$ cell epitopes in these patients (48). Hence, there is increasing data that posttranslational modification of self proteins can play a critical role in the development of autoimmunity.

In sum, our studies establish that an autoantibody response to citrullinated proteins, which is indistinguishable from that observed in RA, develops in CIA. Additionally, this report is the first formal demonstration, to our knowledge, that antibodies against citrullinated proteins contribute to the pathogenesis of inflammatory arthritis. However, many questions remain to be answered. For example, how an immune response specific to citrullinated proteins develops in CIA as well as in patients with RA is unknown. Additionally, the relevant targets of these antibodies in joints or in peripheral tissue are not known. Also, whether selection of citrullinated autoantibodies emerges from a preexisting natural antibody repertoire, as our studies suggest, is unclear. Nevertheless, we have shown herein that CIA is a valuable model in which many of these questions may be investigated. Furthermore, knowing that antibodies against citrullinated proteins are involved in the pathogenesis of RA may allow for the development of targeted therapeutics that inhibit these antibodies or their development. Such therapeutic approaches may reduce disease severity in patients with active disease or perhaps even prevent the onset of clinically significant arthritis in susceptible individuals who are still asymptomatic but exhibit anti-CCP antibodies $(15,16)$.

\section{Methods}

Animals and immunizations. CII purified from calf articular cartilage (Elastin Products Company Inc.) was solubilized in $0.1 \mathrm{M}$ acetic acid at a concentration of $4 \mathrm{mg} / \mathrm{ml}$ and stored at $-70^{\circ} \mathrm{C}$. For immunization, CII was emulsified in an equal volume of incomplete Freund's adjuvant (BD Diagnostics) supplemented with $4 \mathrm{mg} / \mathrm{ml}$ M. tuberculosis H37 RA (BD Diagnostics) to make complete Freund's adjuvant (CFA). Six- to eight-week-old DBA/1J male mice (Jackson Laboratory) were immunized intradermally with $0.1 \mathrm{ml} \mathrm{CII} \mathrm{in} \mathrm{CFA}$ or with CFA alone on days 0 and 21 . From days 25 through 35 after the initial immunization, mice were scored daily by an individual blinded to their treatments for signs of arthritis in the paws based on the following scale: 0 , no redness or swelling; 1,1 digit swollen; 2 , 2 digits swollen; 3 , 3 digits swollen; and 4 , entire paw swollen with ankylosis. The scores for each of 4 paws of a mouse were totaled to give a final score with a maximal severity of 16 .

Tolerance in animals was induced by administering $300 \mu \mathrm{g}$ of protein (CII or ovalbumin) or peptide (LXP or LKP; see below) in PBS intravenously daily for 3 days. Three days following the final dose of tolerogen, mice were immunized with CII in CFA according to the same protocol as above, with day 0 of the experiment corresponding to the day on which animals were first immunized with CII in CFA. To overcome tolerance, mice tolerized and challenged as above were then administered either $2 \mathrm{mg}$ total of $1 \mathrm{mg}$ 1042 plus $1 \mathrm{mg} 1618$ or $2 \mathrm{mg}$ of the control HB5 monoclonal antibody described below on days 22 and 28 after the initial CII/CFA challenge.

Passive arthritis was induced by intravenous transfer of a cocktail of monoclonal antibodies against CII (Arthrogen-CIA; Chemicon International) and/or the monoclonal antibodies D513, 1042, or 1618, which specifically bind citrulline-modified fibrinogen. An IgM monoclonal antibody to trinitrophenol-KLH (anti-TNP; BD Biosciences - Pharmingen) and an IgG2a monoclonal antibody specific to human complement receptor 2 (HB5) were administered as negative controls. Previous studies have demonstrated that HB5 does not bind murine complement receptor $2(32,33)$ and therefore does not modulate the complement system in mice. Intraperitoneal injection of $50 \mu \mathrm{g} /$ mouse of LPS followed 3 days later after administration of each antibody. Arthrogen was titrated to determine the dose that would yield submaximal disease in animals for use in combination with anticitrullinated fibrinogen monoclonal antibodies and the control antibody. All animal work was approved and performed under the guidelines set by the University of Colorado Institutional Animal Care and Use Committee.

Peptides. LXP (SHQESTcitGRSRGRSGRSGS) and LRP (SHQESTRGRSRGRSGRSGS) were synthesized as described (12). Another peptide, in which all arginine residues were substituted with lysine, was also synthesized and served as an additional control (LKP; SHQESTKGKSKGKSGKSGS). Quality control by mass spectroscopy and HPLC revealed the peptides to be of the appropriate sequence and more than $95 \%$ pure.

Measurement of antibodies. Sera from each mouse were collected from the tail vein on the initial day of immunization and every 7 days thereafter. On the day of sacrifice, sera were collected by cardiac puncture. Anti-CCP antibody titers were determined using the DIASTAT Anti-CCP2 kit (second generation peptides; Axis-Shield Diagnostics Ltd.) following manufacturer's instructions with the following modifications: for most experiments mouse sera were diluted 1:10 or 1:100 in sample diluent, and the secondary antibody was substituted with alkaline phosphatase-conjugated goat anti-mouse IgM, IgG, IgG1, IgG2a, IgG2b, or IgG3 (CALTAG Laboratories) diluted 1:1,000 in PBS. The kit standard was utilized for all ELISAs without modification of the secondary antibody to maintain consistency between all plates and to demonstrate relative reactivity between isotypes.

Anti-CII antibody titers were assayed by ELISA. Immulon 2HB 96-well plates (DYNEX Technologies) were coated with $0.5 \mu \mathrm{g} /$ well bovine CII (Chondrex Inc.) overnight at $4^{\circ} \mathrm{C}$. Plates were washed 3 times with PBS containing $0.5 \%$ Tween-20 and $1 \%$ BSA and then blocked with $10 \%$ BSA in PBS for 4 hours at $4^{\circ} \mathrm{C}$. Mouse sera were diluted 1:500, 1:1,000, or 1:2,000 in PBS and $50 \mu \mathrm{l} /$ well added in duplicate; antibodies were then allowed to bind overnight at $4{ }^{\circ} \mathrm{C}$. For each plate, a standard consisting of pooled sera from arthritic mice was applied. Plates were washed 3 times with PBS $/ 0.5 \%$ Tween-20. Horseradish peroxidase-conjugated (HRP-conjugated) goat anti-mouse IgM, IgG, IgG1, IgG2a, IgG2b, or IgG3 (CALTAG Laboratories) diluted 1:1,000 in PBS was added at $50 \mu \mathrm{l} /$ well and allowed to bind for 4 hours at $4^{\circ} \mathrm{C}$. Again, plates were washed 3 times with PBS/ $0.5 \%$ Tween20. ELISA was developed for 30 minutes using $50 \mu \mathrm{l} /$ well, $1 \% \mathrm{H}_{2} \mathrm{O}_{2}$, in $2,2^{\prime}$ azinobis(3-ethylbenzthiazoline-6-sulfonic acid) (ABTS) solution and read at $405 \mathrm{~nm}$ with a $492-\mathrm{nm}$ reference filter.

Anti-filaggrin antibody reactivity was determined by indirect immunofluorescence. Undiluted sera or sera diluted 1:10 in PBS from arthritic, adjuvant control, and untreated mice were applied to rat esophageal sections (Scimedx Corporation) for 1 hour at room temperature with humidity. The slides were then washed 3 times for 5 minutes in PBS. FITCconjugated goat anti-mouse IgG (BD Biosciences - Pharmingen) was applied for 1 hour at room temperature with humidity. The slides were again washed 3 times for 5 minutes in PBS and a coverslip placed on the slide. Reactivity was visualized under a fluorescent microscope. For peptide competition of serum binding to tissue, sera were diluted 1:10 in PBS, with $100 \mu \mathrm{g} / \mathrm{ml} \mathrm{LAP}$ in PBS, or with $100 \mu \mathrm{g} / \mathrm{ml} \mathrm{LXP}$ in PBS and incubated at $4{ }^{\circ} \mathrm{C}$ overnight before being applied to tissue sections.

Antibodies against unmodified and citrullinated fibrinogen were assessed by Western blot analysis. Human fibrinogen (Sigma-Aldrich) was deiminated in vitro by rabbit type II PAD (Sigma-Aldrich) at a substrate/enzyme ratio

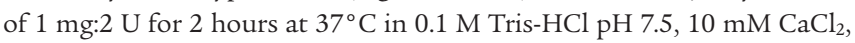
and $5 \mathrm{mM}$ DTT. The reaction was stopped by the addition of $20 \mathrm{mM}$ EDTA. As the unmodified fibrinogen control, fibrinogen and PAD were combined 
as described, but $20 \mathrm{mM}$ EDTA was added immediately to prevent enzyme activity on the substrate. For Western blotting, $2.5 \mu \mathrm{g}$ of unmodified or citrullinated fibrinogen was loaded into each well of a NuPAGE $10 \%$ BisTris gel (Invitrogen Corp.) and transferred onto a nitrocellulose membrane (Amersham Pharmacia Biotech). The membrane was blocked for 1 hour at room temperature with $10 \%$ dry milk in PBS. Pooled sera from RA patients, arthritic mice, or control mice were diluted 1:100 in PBS with 1\% BSA and incubated with the membrane overnight at $4{ }^{\circ} \mathrm{C}$. The membrane was then washed with PBS/0.5\% Tween-20 3 times for 10 minutes each wash. HRP-conjugated goat anti-human or anti-mouse IgG (CALTAG Laboratories) diluted 1:2,000 in PBS was incubated with the membrane for 2 hours at room temperature. After washing the membrane with PBS/0.5\% Tween-20 3 times for 10 minutes, equal volumes of luminescence reagent and oxidizing reagent (ECL reagent; Amersham Pharmacia Biotech) were applied for 1 minute. The membrane was then transferred to a plastic bag and film was exposed.

Histologic analysis of joints and immunohistochemistry. At the time of sacrifice on day 35 after immunization with CII in CFA, paws were removed and placed in $10 \%$ buffered formalin. Tissue was then decalcified in $5 \%$ formic acid for 3 days, followed by embedding in paraffin. Sections of $8 \mu \mathrm{m}$ were stained with toluidine blue and evaluated by a trained observer blinded to the treatment group. Each mouse was assessed a histologic disease activity score from 0 to 5 determined by inflammation, pannus formation, cartilage damage, bone damage, and an overall score based on 5 joint sets per animal.

For immunohistochemistry, $5-\mu \mathrm{m}$ paraffin-embedded sections were fixed to Superfrost Plus microscope slides (Fisher Scientific International). Slides were heated to $60^{\circ} \mathrm{C}$ until paraffin was melted. Tissue was fixed to the slide and rehydrated by soaking in xylenes for 2 changes, 5 minutes each, followed by 2 changes, 2 minutes each, of 100\% ethanol, 95\% ethanol, 70\% ethanol, and PBS. Bovine testicular hyaluronidase $(10,000 \mathrm{U} / \mathrm{ml})$ (Sigma-Aldrich) was applied to the tissue for 30 minutes. Intrinsic peroxidase activity was then inactivated by incubation for 1 hour in methanol with $3 \% \mathrm{H}_{2} \mathrm{O}_{2}$. After washing tissue 2 times for 5 minutes in PBS, tissue antigens were immunostained using a Mouse on Mouse (M.O.M.) tissue-staining kit (Vector Laboratories). D513, 1042, and 1610 were diluted to $4 \mu \mathrm{g} / \mathrm{ml}$ for application to tissue, and appropriate secondary antibody at $1.5 \mu \mathrm{g} / \mathrm{ml}$ was substituted when necessary. Stained sections were examined by light microscopy.

Development and purification of monoclonal antibodies. IgM monoclonal antibodies were developed from splenocytes collected from a naive, wildtype C57BL/6 mouse that were fused with the SP2/0-AG14 myeloma cell line by the standard protocol to establish hybridomas. To create IgG monoclonal antibodies, splenocytes and draining LN cells from a mouse with CIA were fused with the FOX-NY myeloma cell line. Successful fusions were screened by Western blot and selected based on specific reactivity with citrullinated fibrinogen. One positive IgM-producing hybridoma, D513, and 2 positive IgG-producing hybridomas, 1042 and 1618 , were cloned further and studied.

Antibodies from exhausted supernatant of cultured D513, 1042, and 1618 cells were affinity purified. Supernatant from D513 was applied to a column of agarose beads coated with antibodies against human IgM, $\mu$ chain (Sigma-Aldrich), cross-reactive with mouse IgM. Supernatant from 1042 and 1618 was applied to a column of protein G-coated sepharose beads (Amersham Biosciences). Bound antibody was eluted with $0.1 \mathrm{M}$ glycine, $\mathrm{pH} 2.3$, and collected into $1.5 \mathrm{M}$ Tris, $\mathrm{pH}$ 8.8. Eluted antibody was dialyzed against PBS, pH 7.4, for 48 hours and concentrated using centrifugal filtration (Centricon Plus-20; Millipore). Antibody concentration was determined by the $\mathrm{A}_{280}$ of the sample, and purity was confirmed by running on a $10 \%$ Bis-Tris gel.

Reactivity of the purified monoclonal antibody was confirmed by applying $10 \mu \mathrm{g} / \mathrm{ml}$ monoclonal antibody in PBS to Western blots of unmodified and citrullinated fibrinogen as described previously. The secondary anti- bodies used in these analyses were HRP-conjugated goat anti-mouse IgM for D513 and HRP-conjugated goat anti-mouse IgG for 1042 and 1618, diluted 1:2,000 in PBS. To demonstrate specificity for fibrinogen on the blot, $200 \mu \mathrm{g} / \mathrm{ml}$ unmodified fibrinogen or citrullinated fibrinogen was preincubated with $10 \mu \mathrm{g} / \mathrm{ml} \mathrm{D513}$ for 1 hour at room temperature prior to applying to the Western blot.

Relative binding to unmodified fibrinogen, citrullinated fibrinogen, and CII was determined by ELISA. Wells of Immulon $2 \mathrm{HB}$ plates (DYNEX Technologies) were coated with $100 \mu \mathrm{l} /$ well of $5 \mu \mathrm{g} / \mathrm{ml}$ monoclonal antibodies D513, 1042, or 1618 in PBS overnight at $4^{\circ} \mathrm{C}$. The plates were washed 3 times with PBS $/ 0.5 \%$ Tween- 20 and then blocked with $200 \mu \mathrm{l} /$ well $1 \%$ BSA in PBS for 1 hour at room temperature. Biotinylated unmodified fibrinogen, citrullinated fibrinogen, or CII was applied at increasing concentrations from 0 pmol to $450 \mathrm{pmol}$ for D513 or from 0 pmol to 90 pmol for 1042 and 1618. The protein was allowed to bind antibody for 1 hour at room temperature. The plates were washed 5 times with PBS/0.5\% Tween-20. We added $100 \mu \mathrm{l} /$ well of streptavidin-HRP diluted 1:5,000 in PBS to wells and allowed it to bind for 1 hour at room temperature. After washing the plates 5 times with PBS/0.5\% Tween-20, the plates were developed with ABTS solution described above and read at $405 \mathrm{~nm}$ with a $492 \mathrm{~nm}$ reference filter.

The IgG subclass of 1042 and 1618 was determined by a modified sandwich ELISA (data not shown). A 96-well Immulon 1B plate (DYNEX Technologies) was coated with $100 \mu \mathrm{l} /$ well of $2 \mu \mathrm{g} / \mathrm{ml}$ goat anti-mouse $\mathrm{IgG} 1$, IgG2a, IgG2b, or IgG3 overnight at $4{ }^{\circ} \mathrm{C}$. The plate was washed 3 times with PBS $/ 0.5 \%$ Tween- 20 followed by blocking with $200 \mu \mathrm{l} /$ well $1 \%$ BSA in PBS for 1 hour at room temperature. We added $100 \mu \mathrm{l} /$ well of $4 \mu \mathrm{g} / \mathrm{ml}$ biotinylated 1042 or 1618 in duplicate to wells coated with each of the isotypes. A standard consisting of purified mouse IgG1, IgG2a, IgG2b, or IgG3 was also applied to wells in duplicate at $100 \mu \mathrm{l} /$ well for 1 hour at room temperature. The plates were washed 5 times with PBS/0.5\% Tween-20. Streptavidin-HRP was diluted 1:5,000 in PBS and applied at $100 \mu \mathrm{l} /$ well to wells in which 1042 or 1618 were applied. Goat anti-mouse IgG (total) was diluted 1:2,000 and applied at $100 \mu \mathrm{l} /$ well to standard wells for 1 hour at room temperature. The plates were washed 7 times with PBS/0.5\% Tween- 20 . The ELISA was then developed for 30 minutes using $50 \mu \mathrm{l} /$ well $1 \% \mathrm{H}_{2} \mathrm{O}_{2}$ in ABTS and read at $405 \mathrm{~nm}$ with a $492 \mathrm{~nm}$ reference filter.

Purified 1042, 1618, and HB5 antibodies and unmodified fibrinogen, citrullinated fibrinogen, and CII were biotinylated by adding $20 \mathrm{mmol}$ excess sulfo-NHS-LC-biotin (Pierce Biotechnology) and incubating for 2 hours on ice. Unbound biotin was removed by dialysis against PBS for 48 hours.

Array analyses of sera and monoclonal antibodies. Synovial antigen arrays containing proteins and overlapping peptides representing autoantigen candidates in RA and CIA were produced as previously described (19). Arrays were probed with 1:150 dilutions of sera derived from mice with CIA tolerized with LXP or LKP, or $0.5 \mu$ g of purified monoclonal antibody, followed by detection of antibody binding with Cy3-conjugated anti-mouse IgG/M secondary antibody or a Cy3-avidin conjugate (Jackson ImmunoResearch Laboratories Inc.). The significance analysis of microarrays algorithm (49) was applied to identify antigen features with differences in array reactivity between LKP- and LXP-treated mice with CIA or between duplicate arrays probed with D513, 1042, 1618, and secondary reagents. Cluster software (version 2.11) and TreeView software (version 1.60) were used to order and display the results, respectively (50). Additional detailed protocols have been previously published $(19,51)$. Supplemental Table 1 displays selected antigens and their sequences that are on this array.

Collection and Western blot of animal tissues. Mice were immunized with CFA alone or CII in CFA as described above. Tissue was collected from 3 mice of each group: unimmunized; CFA, day 7 after immunization; CFA, day 35; CIA, day 7; and CIA, day 35. Skin at the site of immunization, draining 
inguinal LNs, and synovium were dissected from the mice and immediately frozen in liquid nitrogen and stored at $-70^{\circ} \mathrm{C}$ until processing. Tissue was processed by homogenization in $1 \mathrm{ml}$ RIPA buffer (1\% Triton X100, $0.5 \%$ deoxycholic acid, $150 \mathrm{mM} \mathrm{NaCL}, 20 \mathrm{mM} \beta$-glycerophosphate, $20 \mathrm{mM}$ Tris, $\mathrm{pH}$ 8.0, $5 \mathrm{mM}$ EGTA, $3 \mathrm{mM} \mathrm{MgCl}_{2}$, and $0.1 \% \mathrm{SDS}$ in water) containing 1 $\mathrm{mM}$ DTT and 1 tablet protease inhibitor cocktail (Complete Mini, EDTA free; Roche Applied Science). Homogenized samples were placed on ice for 15 minutes and then centrifuged at $4{ }^{\circ} \mathrm{C}, 10,000 \mathrm{~g}$ for 15 minutes. The supernatant was collected and the pellet discarded. Protein concentration was determined by the Bio-Rad BSA protein assay (Bio-Rad). From each sample, $20 \mu \mathrm{g}$ protein was loaded onto $10 \%$ Bis-Tris gels and run at $80 \mathrm{~V}$ until the loading dye front ran just off the gel. The protein was then transferred to nitrocellulose at $75 \mathrm{~V}$ for 1 hour. The blot was blocked overnight at $4{ }^{\circ} \mathrm{C}$ with $10 \%$ milk in PBS. Primary antibodies, either anti-citrulline (Biogenesis Ltd.), D513, biotinylated 1042, or biotinylated 1618 monoclonal antibodies, were applied to the blot at a concentration of $5 \mu \mathrm{g} / \mathrm{ml}$ for 1 hour at room temperature. After washing the blot 3 times for 10 minutes with PBS containing $0.5 \%$ Tween-20, secondary antibody, HRP-conjugated goat anti-rabbit IgG, or anti-mouse IgM was diluted 1:2,000 in PBS, or HRP-conjugated streptavidin was diluted 1:5,000 in PBS and applied to the blot for 1 hour at room temperature. The blot was again washed with
PBS/0.5\% Tween-20 3 times for 10 minutes. ECL reagent (Amersham Pharmacia Biotech) was applied for 1 minute. The membrane was then transferred to a plastic bag and film was exposed.

Statistics. All statistical analyses were performed using GraphPad Prism version 4 (GraphPad Software). Specific tests performed are noted within figure legends.

\section{Acknowledgments}

Funding for these studies was provided by the Smyth Professorship in Rheumatology (V.M. Holers), Medical Scientist Training Program grant T32 GM008497 (K.A. Kuhn), NIH NHLBI contract N01 HV 28183, and the Department of Veterans Affairs (W.H. Robinson).

Received for publication April 21, 2005, and accepted in revised form January 3, 2006.

Address correspondence to: V. Michael Holers, Department of Medicine, University of Colorado Health Sciences Center, Box B115, 4200 East Ninth Avenue, Denver, Colorado 80262, USA. Phone: (303) 315-7952; Fax: (303) 315-5540; E-mail: michael.holers@uchsc.edu.
1. Arnett, F.C., et al. 1988. The American Rheumatism Association 1987 revised criteria for the classification of rheumatoid arthritis. Arthritis Rheum. 31:315-324.

2. Aho, K., Palusuo, T., and Kurki, P. 1994. Marker antibodies of rheumatoid arthritis: diagnostic and pathogenetic implications. Semin. Arthritis Rheum. 23:379-387.

3. Nienhuis, R.L., and Mandema, E. 1964. A new serum factor in patients with rheumatoid arthritis; the antiperinuclear factor. Ann. Rheum. Dis. 23:302-305.

4. Young, B.J., Mallya, R.K., Leslie, R.D., Clark, C.J., and Hamblin, T.J. 1979. Anti-keratin antibodies in rheumatoid arthritis. Br. Med. J. 2:97-99.

5. Vincent, C., et al. 1989. High diagnostic value in rheumatoid arthritis of antibodies to the stratum corneum of rat oesophagus epithelium, socalled 'antikeratin antibodies'. Ann. Rheum. Dis. 48:712-722.

6. Hoet, R.M., Boerbooms, A.M., Arends, M., Ruiter, D.J., and van Venrooij, W.J. 1991. Antiperinuclear factor, a marker autoantibody for rheumatoid arthritis: colocalisation of the perinuclear factor and profilaggrin. Ann. Rheum. Dis. 50:611-618.

7. Simon, M., et al. 1993. The cytokeratin filamentaggregating protein filaggrin is the target of the so-called "antikeratin antibodies," autoantibodies specific for rheumatoid arthritis. J. Clin. Invest. 92:1387-1393.

8. Steinert, P.M., Cantieri, J.S., Teller, D.C., LonsdaleEccles, J.D., and Dale, B.A. 1981. Characterization of a class of cationic proteins that specifically interact with intermediate filaments. Proc. Natl. Acad. Sci. U. S. A. 78:4097-4101.

9. Resing, K.A., Dale, B.A., and Walsh, K.A. 1985 Multiple copies of phosphorylated filaggrin in epidermal profilaggrin demonstrated by analysis of tryptic peptides. Biochemistry. 24:4167-4175.

10. Harding, C.R., and Scott, I.R. 1983. Histidine-rich proteins (filaggrins): structural and functional heterogeneity during epidermal differentiation. J. Mol. Biol. 170:651-673.

11. Watanabe, K., et al. 1988. Combined biochemical and immunochemical comparison of peptidylarginine deiminases present in various tissues. Biochim. Biophys. Acta. 966:375-383.

12. Schellekens, G.A., et al. 1998. Citrulline is an essential constituent of antigenic determinants recognized by rheumatoid arthritis-specific autoantibodies. J. Clin. Invest. 101:273-281.
13. Girbal-Neuhauser, E., et al. 1999. The epitopes targeted by the rheumatoid arthritis-associated antifilaggrin autoantibodies are posttranslationally generated on various sites of (pro)filaggrin by deimination of arginine residues. J. Immunol. 162:585-594.

14. Schellekens, G.A., et al. 2000. The diagnostic properties of rheumatoid arthritis antibodies recognizing a cyclic citrullinated peptide. Arthritis Rheum. 43:155-163.

15. Rantapaa-Dahlqvist, S., et al. 2003. Antibodies against cyclic citrullinated peptide and IgA rheumatoid factor predict the development of rheumatoid arthritis. Arthritis Rheum. 48:2741-2749.

16. Nielen, M.M., et al. 2004. Specific autoantibodies precede the symptoms of rheumatoid arthritis: a study of serial measurements in blood donors. Arthritis Rheum. 50:380-386.

17. Masson-Bessiere, C., et al. 2001. The major synovial targets of the rheumatoid arthritis-specific antifilaggrin autoantibodies are deiminated forms of the alpha- and beta-chains of fibrin. J. Immunol. 166:4177-4184.

18. Vossenaar, E.R., et al. 2004. Rheumatoid arthritis specific anti-Sa antibodies target citrullinated vimentin. Arthritis Res. Ther. 6:R142-R150.

19. Hueber, W., et al. 2005. Antigen microarray profiling of autoantibodies in rheumatoid arthritis. Arthritis Rheum. 52:2645-2655.

20. Courtenay, J.S., Dallman, M.J., Dayan, A.D., Martin, A., and Mosedale, B. 1980. Immunisation against heterologous type II collagen induces arthritis in mice. Nature. 283:666-668.

21. Corthay, A., Johansson, A., Vestberg, M., and Holmdahl, R. 1999. Collagen-induced arthritis development requires alpha beta $\mathrm{T}$ cells but not gamma delta T cells: studies with T cell-deficient (TCR mutant) mice. Int. Immunol. 11:1065-1073.

22. Ranges, G.E., Sriram, S., and Cooper, S.M. 1985 Prevention of type II collagen-induced arthritis by in vivo treatment with anti-L3T4. J. Exp. Med. 162:1105-1110.

23. Wooley, P.H., Luthra, H.S., Stuart, J.M., and David, C.S. 1981. Type II collagen-induced arthritis in mice. I. Major histocompatibility complex (I region) linkage and antibody correlates. J. Exp. Med. 154:688-700

24. Rosloniec, E.F., Whittington, K.B., Brand, D.D., Myers, L.K., and Stuart, J.M. 1996. Identification of MHC class II and TCR binding residues in the type II collagen immunodominant determinant mediating collagen-induced arthritis. Cell Immunol. 172:21-28.

25. Mussener, A., Litton, M.J., Lindroos, E., and Klareskog, L. 1997. Cytokine production in synovial tissue of mice with collagen-induced arthritis (CIA). Clin. Exp. Immunol. 107:485-493.

26. Thornton, S., Duwel, L.E., Boivin, G.P., Ma, Y., and Hirsch, R. 1999. Association of the course of collagen-induced arthritis with distinct patterns of cytokine and chemokine messenger RNA expression. Arthritis Rheum. 42:1109-1118.

27. Mauri, C., Williams, R.O., Walmsley, M., and Feldmann, M. 1996. Relationship between Th1/Th2 cytokine patterns and the arthritogenic response in collagen-induced arthritis. Eur. J. Immunol. 26:1511-1518.

28. Watson, W.C., and Townes, A.S. 1985. Genetic susceptibility to murine collagen II autoimmune arthritis. Proposed relationship to the IgG2 autoantibody subclass response, complement $\mathrm{C} 5$, major histocompatibility complex (MHC) and non-MHC loci. J. Exp. Med. 162:1878-1891.

29. Lopez-Hoyos, M., et al. 2003. Defects in the regulation of $\mathrm{B}$ cell apoptosis are required for the production of citrullinated peptide autoantibodies in mice. Arthritis Rheum. 48:2353-2361.

30. Myers, L.K., Stuart, J.M., Seyer, J.M., and Kang, A.H. 1989. Identification of an immunosuppressive epitope of type II collagen that confers protection against collagen-induced arthritis. J. Exp. Med. 170:1999-2010.

31. Myers, L.K., et al. 1993. T cell epitopes of type II collagen that regulate murine collagen-induced arthritis. J. Immunol. 151:500-505.

32. Carel, J.C., Myones, B.L., Frazier, B., and Holers, V.M. 1990. Structural requirements for C3d,g/ Epstein-Barr virus receptor (CR2/CD21) ligand binding, internalization, and viral infection. J. Biol. Chem. 265:12293-12299.

33. Molina, H., et al. 1991. Analysis of Epstein-Barr virus-binding sites on complement receptor 2 (CR2/CD21) using human-mouse chimeras and peptides. At least two distinct sites are necessary for ligand-receptor interaction. J. Biol. Chem. 266:12173-12179.

34. Vossenaar, E.R., et al. 2003. Citrullination of synovial proteins in murine models of rheumatoid arthritis. Arthritis Rheum. 48:2489-2500.

35. Terato, K., et al. 1992. Induction of arthritis with monoclonal antibodies to collagen. J. Immunol. 
148:2103-2108.

36. Maccioni, M., et al. 2002. Arthritogenic monoclonal antibodies from K/BxN mice. J. Exp. Med. 195:1071-1077.

37. Vossenaar, E.R., et al. 2004. Absence of citrullinespecific autoantibodies in animal models of autoimmunity. Arthritis Rheum. 50:2370-2372.

38. Hang, L., Theofilopoulos, A.N., and Dixon, F.J. 1982. A spontaneous rheumatoid arthritis-like disease in MRL/1 mice. J. Exp. Med. 155:1690-1701.

39. Hida, S., Miura, N.N., Adachi, Y., and Ohno, N. 2004. Influence of arginine deimination on antigenicity of fibrinogen. J. Autoimmun. 23:141-150.

40. Suzuki, A., et al. 2003. Functional haplotypes of PADI4, encoding citrullinating enzyme peptidylarginine deiminase 4 , are associated with rheumatoid arthritis. Nat. Genet. 34:395-402.

41. Boyde, T.R., and Rahmatullah, M. 1980. Optimization of conditions for the colorimetric determination of citrulline, using diacetyl monoxime. Anal. Biochem. 107:424-431.
42. Vossenaar, E.R., et al. 2004. Expression and activity of citrullinating peptidylarginine deiminase enzymes in monocytes and macrophages. Ann. Rheum. Dis. 63:373-381.

43. Backlund, J., et al. 2002. Glycosylation of type II collagen is of major importance for $\mathrm{T}$ cell tolerance and pathology in collagen-induced arthritis. Eur. J. Immunol. 32:3776-3784.

44. Backlund, J., et al. 2002. Predominant selection of T cells specific for the glycosylated collagen type II epitope (263-270) in humanized transgenic mice and in rheumatoid arthritis. Proc. Natl. Acad. Sci. U. S. A. 99:9960-9965.

45. Utz, P.J., Hottelet, M., Schur, P.H., and Anderson, P. 1997. Proteins phosphorylated during stressinduced apoptosis are common targets for autoantibody production in patients with systemic lupus erythematosus. J. Exp. Med. 185:843-854.

46. Arentz-Hansen, H., et al. 2000. The intestinal T cell response to alpha-gliadin in adult celiac disease is focused on a single deamidated glutamine targeted by tissue transglutaminase. J. Exp. Med. 191:603-612.

47. Anderson, R.P., Degano, P., Godkin, A.J., Jewell, D.P., and Hill, A.V. 2000. In vivo antigen challenge in celiac disease identifies a single transglutaminase-modified peptide as the dominant A-gliadin T-cell epitope. Nat. Med. 6:337-342.

48. Dieterich, W., et al. 1997. Identification of tissue transglutaminase as the autoantigen of celiac disease. Nat. Med. 3:797-801.

49. Tusher, V.G., Tibshirani, R., and Chu, G. 2001. Significance analysis of microarrays applied to the ionizing radiation response. Proc. Natl. Acad. Sci.U.S. A. 98:5116-5121.

50. Eisen, M.B., Spellman, P.T., Brown, P.O., and Botstein, D. 1998. Cluster analysis and display of genome-wide expression patterns. Proc. Natl. Acad. Sci. U. S. A. 95:14863-14868.

51. Robinson, W.H., et al. 2002. Antigen arrays for multiplex characterization of autoantibody responses. Nat. Med. 8:295-301. 